O CONCEITO DE BULLYING ESCOLAR: UMA CRÍTICA À IDEOLOGIA SUBJACENTE ATRAVÉS DO PENSAMENTO CONSTRUCIONISTA CRÍTICO Jairo José dos Santos Junior

\author{
O CONCEITO DE BULLYING ESCOLAR: UMA CRÍTICA À \\ IDEOLOGIA SUBJACENTE ATRAVÉS DO PENSAMENTO \\ CONSTRUCIONISTA CRÍTICO
}

\title{
THE CONCEPT OF SCHOOL BULLYING: A CRITICISM TO THE UNDERLYING IDEOLOGY THROUGH CRITICAL CONSTRUCTIONIST THOUGHT
}

Jairo José dos Santos Junior ${ }^{1}$

\section{RESUMO}

Este artigo se debruça sobre uma análise crítica do conceito de bullying escolar a partir de uma compreensão teórica que será designada como Construcionista Crítica, teorização esta que vem sendo amplamente praticada pelas ciências humanas, embora nem sempre encerrada sob tal denominação. Partindo de sua hipótese geral, que vislumbra a realidade humano-social como produto da construção humana, cultural e histórica, o Construcionismo Crítico exprime a própria vocação das ciências humanas ao oporem-se abertamente às tentativas recorrentes de biologização do social, feitas principalmente pelas ciências médicas e biológicas. Assim, busca-se aqui refletir inicialmente sobre o histórico geral do problema da violência escolar no mundo e como o conceito de bullying escolar se enquadra neste contexto; apontar o caráter ideológico por trás das verdades anunciadas pelo discurso que subjaz a compreensão do bullying; e sugerir esta nova alternativa teórica e metodológica que permite pinçar o bullying do discurso hegemônico que o subjaz e que produz suas verdades inquestionáveis e firmemente estabelecidas para problematizá-lo através de categorias intrinsecamente inerentes às ciências humanas e sociais.

\footnotetext{
${ }^{1}$ Professor de Sociologia da Rede Pública de Ensino do Rio Grande do Norte. Mestre em Ciências Sociais.
} 


\title{
O CONCEITO DE BULLYING ESCOLAR: UMA CRÍTICA À IDEOLOGIA SUBJACENTE ATRAVÉS DO PENSAMENTO CONSTRUCIONISTA CRÍTICO Jairo José dos Santos Junior
}

Palavras-Chave: Violência escolar. Bullying escolar. Construcionismo crítico. Ideologia.

\begin{abstract}
This article focuses on a critical analysis of the concept of school bullying from a theoretical understanding that will be designated as Critical Constructionist, which has been widely practiced by the human sciences, although not always enclosed under such denomination. Starting from its general hypothesis, which envisions human-social reality as a product of human, cultural and historical construction, Critical Constructionism expresses the very vocation of the human sciences by openly opposing the recurrent attempts at the biologization of the social, made mainly by the sciences medical and biological. Thus, it is sought here to reflect initially upon the general history of the problem of school violence in the world and how the concept of school bullying fits in this context; to point out the ideological character behind the truths announced by the discourse that underlies the understanding of bullying; and to suggest this new theoretical and methodological alternative that allows to pick up the bullying of the hegemonic discourse that underlies it and that produces its truths unquestionable and firmly established to problematize it through categories intrinsically inherent to the human and social sciences.
\end{abstract}

Keywords: School violence. School bullying. Critical Constructionism. Ideology.

\section{INTRODUÇÃO}

Cronologicamente, o fenômeno da violência escolar é mais antigo do que se pensa. Vem sendo tema de estudos nos Estados Unidos desde a década de 1950. No Brasil, as primeiras análises se iniciam apenas na década de 1970. Deste período até hoje, o recrudescimento do problema da violência evoluiu desde depredações ou danos patrimoniais às escolas, para se concentrar atualmente no seio das relações interpessoais, ou mais precisamente, sob a forma de agressões, assédio e formação de gangues destinadas ao conflito geral (SPOSITO, 2011). Com o final da década de 1990 


\section{O CONCEITO DE BULLYING ESCOLAR: UMA CRÍTICA À IDEOLOGIA SUBJACENTE ATRAVÉS DO PENSAMENTO CONSTRUCIONISTA CRÍTICO Jairo José dos Santos Junior}

e início dos anos 2000 a violência interpessoal escolar já se configurara como um grave problema social, apresentando-se numa ampla variedade de formas: indisciplina; delinquência; problemas relacionais entre os personagens da escola; tráfico de drogas; formação de gangues; prostituição forçada, etc.

Em meio a esta escalada de violência, uma nova definição de agressão passou a chamar a atenção dos estudiosos da temática da violência estudantil no final do século XX, sobretudo após o aumento do número de suicídios entre crianças e adolescentes na Europa a partir da década de 1970. Tal fato levou diversos especialistas a buscarem as causas desta nascente epidemia que se alastrou primeiramente para a Suécia e a Dinamarca (1970); e depois, para a Noruega (1980) e o resto do continente europeu (FANTE, 2008, p. 35-36). Na Noruega em particular, o fenômeno ganhou uma designação inédita: bullying.

Segundo Fante (2008), este termo de origem inglesa foi cunhado na década de 1970 pelo pesquisador norueguês Dan Olweus, da Universidade de Bergen, na Noruega, para descrever os comportamentos agressivos, intencionais e repetitivos contra uma ou mais pessoas, sem motivação evidente e realizada numa perspectiva de desequilíbrio de poder entre os envolvidos. Não se trata, pois, de uma prática agressiva ocasional e reativa, mas, sim, deliberada, repetitiva e sutil, já que a autoridade escolar pouco ou nada sabe sobre as agressões.

Antunes \& Zuin (2008) ao procederem numa análise crítica desta "nova" forma de violência, denunciaram como este conceito é pragmatizado por promover um "fazer" científico que preza muito mais pela manutenção da ordem vigente ao invés de colaborar para a emancipação dos indivíduos. Em poucas palavras, tratar-se-ia primeiramente de um recorte dos protagonistas da realidade; sua restruturação comportamental via imperativos morais do como "ser" e "agir" corretos na sociedade; e sua reinserção ao mesmo universo desigual que outrora produziu tal violência. Em suma, a questão do bullying, tal como concebida pelos estudiosos e especialistas do assunto, converte-se num discurso ideológico que preza pela manutenção do sistema vigente e inquestionável em detrimento da real emancipação dos homens e da sociedade (ANTUNES \& ZUIN, 2008, p. 36). 


\section{O CONCEITO DE BULLYING ESCOLAR: UMA CRÍTICA À IDEOLOGIA SUBJACENTE ATRAVÉS DO PENSAMENTO CONSTRUCIONISTA CRÍTICO Jairo José dos Santos Junior}

Partindo das premissas anteriores, o presente trabalho não tem a pretensão de esgotar as análises sobre o tema no que tange a sua problematização conceitual. Além disso, embora proponha tecer considerações críticas ao conceito de bulllying e ao discurso científico que o subjaz, não se pretende diminuir a importância dos vastos e aprofundados estudos empírico-estatísticos que se estabeleceram desde a década de 1970 até hoje. O que se faz, ao longo destas páginas, é solicitar atenção redobrada para a necessidade de não se estudar estes fatos apenas pelo conjunto de dados estatísticos e comparativos entre realidades que muitas vezes são tão diferentes quanto complexas. Parafraseando Antunes \& Zuin (2008 p. 36), "estudar estes fatos requer uma análise não cristalizada que envolva sim sua problematização, ou seja, a análise da dialética entre indivíduo e sociedade, sem deixar seduzir-se pelo falso controle sugerido pelo culto da sistematização pura e simples".

Mas como se procederia para analisar o bullying criticamente e à luz das mediações sociais que o determinam? Como problematizar este tema, apontando o caráter não natural das contradições sociais (desigualdades familiares; de poder; etnocentrismos; conflitos de gênero e de normas; conflitos entre estabelecidos e outsiders etc.) e enfatizá-los nas análises sobre as causas que produzem tanta violência?

Se o primeiro passo de desconstrução já foi aqui apontado, com o desvelamento do caráter ideológico da forma de conceituação do bullying, o segundo consistiria na adoção de uma nova perspectiva epistemológica de investigação desta problemática: a Teoria Construcionista Crítica. Segundo Sousa Filho (2007) tratar-se-ia tal estudo de uma síntese de pressupostos, descobertas e conclusões realizada a partir do que há em comum nos estudos sobre indivíduo, cultura e sociedade, constituindo-se como reflexões de um amplo conjunto de autores provenientes de campos distintos das ciências humanas (antropologia, sociologia, história, filosofia etc.). Se há um postulado que possa resumi-lo é o que afirma que o mundo humano social, em toda sua diversidade e em todos os seus aspectos, é produto de construção humana, social e histórica. Em suma, a realidade social é resultado da ação dos próprios seres humanos em seus espaços de viver e de acordo com suas diferenças culturais e históricas. Tal iniciativa supracitada busca se opor as tentações substancialistas e essencialistas de 
O CONCEITO DE BULLYING ESCOLAR: UMA CRÍTICA À IDEOLOGIA SUBJACENTE ATRAVÉS DO PENSAMENTO CONSTRUCIONISTA CRÍTICO Jairo José dos Santos Junior

biologização do social, feitas principalmente pelas ciências médicas e da natureza. Fato muito comum nas análises sobre o bullying e seus personagens.

Portanto, o presente artigo lança-se num duplo propósito: ao passo que desconstrói criticamente a ideologia que sustenta as "verdades" sobre o bullying; oferece uma alternativa epistemológica de análise crítica que se oponha à tentativa de se conceber o mundo pela dicotomia natureza-cultura, binarismo que só reforça os essencialismos e substancialismos da "metafísica da substância" como suposta causa primeira do homem, de sua realidade e do mundo.

\section{PANORAMA GERAL DO BULLYING ESCOLAR: CONCEITO, CLASSIFICAÇÃO E PREVALÊNCIA}

O bullying é uma palavra de origem inglesa adotada por muitos países para descrever o conjunto de atos de violência física, psicológica ou material, intencionais e repetitivos, praticados por um indivíduo (bully) ou grupo de indivíduos com o objetivo de intimidar ou agredir outro sujeito (ou grupo de sujeitos) incapaz de se defender sozinho (FANTE \& PEDRA, 2008, p. 34). É um termo que abarca diversas ações agressivas (apelidar, ofender, intimidar, discriminar, excluir, isolar, insinuar, bater, chutar furtar etc.); que se manifesta em diversos ambientes (escola, família, trabalho, presídio, igreja, forças armadas etc.); e que envolve pelo menos três tipos de personagens: a vítima; as testemunhas; e o agressor ou bully.

No Brasil, ainda não há uma palavra com alcance semântico capaz de abarcar inteiramente todas as ações bullying; daí o uso do termo em inglês no país, procedimento igualmente adotado por diversas outras nações. Desta forma, tal fenômeno de violência apresenta especificidades/critérios capazes de distingui-lo de outras formas de agressão e intimidação: são ações repetitivas contra a mesma vítima num período prolongado de tempo; o desequilíbrio de poder produzido, que dificulta a defesa da vítima; a ausência de motivos que justifiquem os ataques; e os sentimentos negativos e sequelas emocionais mobilizados ao longo da agressão. Tais critérios, estabelecidos por Olweus (1999), especificam este subconjunto de comportamentos 


\section{O CONCEITO DE BULLYING ESCOLAR: UMA CRÍTICA À IDEOLOGIA SUBJACENTE ATRAVÉS DO PENSAMENTO CONSTRUCIONISTA CRÍTICO Jairo José dos Santos Junior}

agressivos, repetitivos e desequilibrados que aparentemente ocorrem sem motivações claras ou veementes.

Costantini (2006) observou que tais comportamentos agressivos e antissociais surgem muito cedo (a partir dos três anos de idade) e acometem qualquer faixa etária ou nível de escolaridade. Além disso, o mesmo autor apontou que, quando não refreado, o comportamento agressivo pode desembocar no futuro em condenações penais, violência doméstica, ou numa personalidade intolerante e antissocial na vida adulta.

Em termos de classificação destas práticas violentas, Martins (2005) classificou três grandes formas de se praticar bullying: os diretos e físicos, com agressões variadas e danos materiais às vítimas; os diretos e verbais, com insultos e comentários indecorosos e vexatórios contra o agredido; e os indiretos, que consistem em estratégias de isolamento social, manipulação e exclusão do grupo, minando o prestígio e a reputação social do acossado. Variantes da agressão também se estendem para além dos muros da escola, como aponta Lopes Neto (2005): o cyberbullying, uma forma digital de agressão que amplia o sofrimento da vítima para além da escola ao se apoiar no uso da tecnologia da comunicação (celulares e internet) para reforçar os ataques. Vários outros autores também elaboraram sistemas classificatórios diversos para enquadrar o fenômeno e tentar compreendê-lo com mais perspicácia.

Fante\& Pedra (2008) apresentaram em sua obra "Bullying escolar: perguntas e respostas" uma caracterização pormenorizada dos protagonistas desta violência: existiriam, segundo eles, as vítimas, que podem ser ou provocadoras ou agressoras; os espectadores; e os agressores. Tal diferenciação de papeis supracitada se aproxima daquilo que afirmaram Lopes Neto (2005) e Smith (2002), quando descreveram os protagonistas da ação como intimidadores (líderes ou seguidores); vítimas (passivas agressivas provocadoras ou aquelas que intimidam outros); e não participantes (os que reforçam a intimidação, os que participam ativamente dela e os que defendem o alvejado ou buscam por ajuda). Independente de quem seja o autor, é notório o uso de estereotipias neste procedimento taxonômico acima adotado.

Outros sistemas de classificação também reforçaram o espectro discursivo que vislumbra tal fenômeno de violência: a variabilidade da prática agressiva entre meninos 
O CONCEITO DE BULLYING ESCOLAR: UMA CRÍTICA À IDEOLOGIA SUBJACENTE ATRAVÉS DO PENSAMENTO CONSTRUCIONISTA CRÍTICO Jairo José dos Santos Junior

e meninas, que atestaria uma maior incidência da violência entre garotos (SIMMONS, 2004); o panorama geral do problema no mundo, esquadrinhado em uma profusão de análises estatísticas e empíricas (FANTE \& PEDRA, 2008, p. 49-57); sua variabilidade em função do espaço em que ocorre (os termos mudam para explicar a ocorrência de um mesmo fenômeno, como por exemplo, a adoção da terminologia assédio moral para vislumbrar a violência em ambientes de trabalho; do termo mob para tratar de assédios de natureza mafiosa; ou as práticas stalking que definem a perseguição as personalidades famosas e do show bussiness. Todos estes estudos quantitativos foram unânimes em afirmar que o fenômeno recrudesce em todo o mundo por se tratar de uma dinâmica psicossocial expansiva, epidêmica e claramente contaminadora entre os envolvidos, sem prognósticos favoráveis para o futuro (FANTE \& PEDRA, 2008).

\section{AS CRÍTICAS AO CONCEITO DE BULLYING ESCOLAR: DA IDEOLOGIA A RESSIGNIFICAÇÃO TERMINOLÓGICA DE VELHOS PROBLEMAS.}

Várias terminologias foram adotadas em diversos países para tratar deste fenômeno peculiar de violência: mobbing (Noruega e Dinamarca); mobbning (Suécia e Finlândia); hercèlement quotidien (França); prepotenza ou bullismo (Itália); yjime (Japão); agression en untershulern (Alemanha); acoso e amenaza entre escolares ou intimidación (Espanha). A terminologia inglesa bullying, no entanto, é a mais adotada em todo o mundo pelos países que buscam combater o problema.

Aqui emerge a primeira crítica: a que questiona o hábito, cada vez mais comum, de se cunhar novos nomes para explicar fenômenos sociais antigos (ALBINO \& TERÊNCIO, 2012, p. 9). Dentro desta perspectiva, o bullying, de acordo com Fante (2005, p. 29) seria na verdade um fenômeno novo e velho ao mesmo tempo: novo porque vem sendo objeto de investigação e de estudos nas últimas décadas com ares de novidade; e velho por se tratar de uma forma de violência que sempre existiu nas escolas e que até hoje ocorre despercebida da maioria dos profissionais de educação, familiares e estudiosos. Embora se revista do ar de novidade, esta terminologia consistiria numa ressignificação de velhos problemas sociais, tais como a homofobia; o preconceito; a transfobia; a misoginia, o racismo, etc. Basta tomar como exemplo as 


\section{O CONCEITO DE BULLYING ESCOLAR: UMA CRÍTICA À IDEOLOGIA SUBJACENTE ATRAVÉS DO PENSAMENTO CONSTRUCIONISTA CRÍTICO Jairo José dos Santos Junior}

obras atuais de estudiosos do assunto e seu perfil excessivamente taxonômico, como por exemplo, Calhau (2010), no qual o autor destaca, em seu livro, pelo menos sete modalidades da prática bullying que, na verdade, apenas descreveriam formas de intimidação antigas, complexas e há muito significadas e decodificadas por diversos saberes científicos.

Já a segunda crítica se insere no pioneirismo dos pesquisadores Deborah Christina Antunes e Antônio Álvaro Soares Zuin (2008), cujo estudo desnuda criticamente a ideologia por trás da operacionalização do conceito bullying em prol da conservação da realidade e de sua hegemonia institucional.

Aqui, faz-se mister debater um pouco sobre o conceito de ideologia. Não propriamente aquele sentido outorgado por Marx (1986) enquanto sinônimo de uma inversão na imagem que a realidade social oferece de si mesma quanto aos seus fundamentos originadores: uma imagem de algo único, universal, eterno, imodificável e necessário. Marx alega que tal representação ficcional da realidade pela ideologia atende a dois intentos: impor os valores simbólicos/representacionais da classe dominante sobre os dominados; e perpetuar tal forma de dominação, com o auxílio do estado e do domínio dos meios de produção.

Sousa Filho (2007), todavia, vai mais além à discussão do conceito: não se restringindo apenas às análises marxistas que tratam do fenômeno da ideologia (que para ele continuam válidos e justificáveis) seria necessário compreender que:

O conceito de ideologia permite pensar mais aspectos do fenômeno que apenas o ponto de vista de uma classe particular no interesse de sua dominação. Pelos próprios estudos antropológicos e sociológicos, torna-se possível pensar a ideologia como fenômeno ligado aos efeitos de sentido de toda estruturação social, ao cada uma delas ratificarem-se no simbólico como Ordens de caráter natural, divino, universal, necessário. Portanto, um fenômeno que não é exclusivo da sociedade fundada na divisão de classes e na separação entre sociedade e poder do Estado, sociedades capitalistas ou outras. Nem fenômeno cuja natureza se restrinja à justificação das relações de produção e para a reprodução do modo de produção. (SOUSA FILHO, 2007, p. 24). 


\section{O CONCEITO DE BULLYING ESCOLAR: UMA CRÍTICA À IDEOLOGIA SUBJACENTE ATRAVÉS DO PENSAMENTO CONSTRUCIONISTA CRÍTICO Jairo José dos Santos Junior}

Partindo da premissa supracitada, de que forma o conceito de ideologia se ampliaria em sua compreensão para além do paradigma marxista? Segundo Sousa Filho (2007), compreendendo-o como o modo de operar de toda a cultura (enquanto sistema de sociedade), que procura naturalizar-se, universalizar-se e eternizar-se, atuando por meio dos discursos sociais que oferecem os sentidos e as significações legitimadoras do que em cada cultura está instituído e aceito. Em suma, a ideologia não consistiria num fenômeno específico desta ou daquela expressão cultural, mas é algo inerente a todo sistema de sociedade, configurando-se como fenômeno de cultura, como o trabalho de toda ordem social na sua busca de se sancionar no simbólico (SOUSA FILHO, 2007, p. 25). É nesta toada que Antunes \& Zuin (2008):

Denunciam que o conceito de bullying, tal como utilizado na maioria dos estudos baseados tão-somente em dados estatísticos e no diagnóstico de sua ocorrência, faz parte de uma ciência instrumentalizada e a serviço da adaptação das pessoas para a manutenção de uma ordem social desigual. Para os autores, a expressão bullying, prontamente importada da literatura internacional para o quadro de estudos brasileiros, pode representar uma tipologia da violência que, na verdade, mascara os processos sociais responsáveis pela sua eclosão - seria, pois, uma forma de alienação. (ALBINO \& TERÊNCIO, 2012, p. 9).

Em linhas gerais, os autores acima aludidos chamam a atenção que para compreender criticamente a problemática do bullying, não se deve deixar de lado a intepretação sociológica das formas de organização social e das forças objetivas que atravessam a sociedade (ANTUNES \& ZUIN, 2008, p. 35). Caso contrário, os estudos com base apenas em dados estatísticos e no diagnóstico do problema; as intervenções baseadas em modelos de uma educação pré-determinada; e a inquestionável necessidade de intervenção via imperativos morais sobre os comportamentos problemáticos fariam parte de um "fazer científico" instrumentalizado e a serviço da mera adaptação dos sujeitos a mesma ordem social desigual que os tencionam. 


\section{O CONCEITO DE BULLYING ESCOLAR: UMA CRÍTICA À IDEOLOGIA SUBJACENTE ATRAVÉS DO PENSAMENTO CONSTRUCIONISTA CRÍTICO Jairo José dos Santos Junior}

Além desta crítica ao falso controle sugerido pela sistematização pura e simples das análises estatísticas e comparativas (ANTUNES \& ZUIN, 2008), outro argumento que toma como base o conceito de ideologia pode igualmente ser aplicado neste momento específico da problematização do conceito bullying: a questão da alienação e da sujeição dos indivíduos ao discurso ideológico dominante.

De acordo com o artigo de Sousa Filho (2007), a ideologia (ou o discurso ideológico da cultura) tem quatro finalidades: a manutenção da dominação de uma ordem estabelecida (realidade social); ocultamento/negação daquilo que ameaça a realidade social (as manifestações do real); desqualificação/estigmatização daquilo que irrompe na realidade e que não foi sancionado pelo simbólico; e o ingresso dos indivíduos na cultura, acompanhado de sua alienação e sujeição ideológica à ordem vigente.

A finalidade da realidade social é manter-se estável; perpétua; e autônoma em relação à ação humana. Para isto, tem que eliminar sua principal ameaça: o real e suas manifestações; e consolidar-se sem questionamentos ou enfrentamentos nas subjetividades e no imaginário social. Esta agonística entre realidade (aquilo que está instituído, legitimado e consagrado simbolicamente entre os indivíduos e instituições) e real (tudo aquilo que não foi simbolizado e, portanto, foracluído do regime das normalidades aceitas conhecido como realidade) coincide com o processo de estruturação social que tem na ideologia a ferramenta de seleção de dados, símbolos e discursos que constituirão as "verdades" que irão assegurar a realidade sua perpetuação e estabilidade.

Tal alienação e sujeição ideológica (uma vez que a ideologia se ancora invisivelmente nas esferas psíquicas, emocionais e cognitivas dos sujeitos - a subjetividade) culminam na produção de indivíduos ideologicamente ativos, que se ignoram como construções socioculturais e históricas, que se creem portadores de substâncias ou essências (divinas, sobrenaturais, da natureza etc.) e que lutam ativamente pela manutenção dos monoteísmos morais, cívicos e institucionais tributários da ordem social hegemônica. 
O CONCEITO DE BULLYING ESCOLAR: UMA CRÍTICA À IDEOLOGIA SUBJACENTE ATRAVÉS DO PENSAMENTO CONSTRUCIONISTA CRÍTICO Jairo José dos Santos Junior

Sendo o bullyinga manifestação de recusa ao diferente, a escola, enquanto espaço institucional por excelência de reprodução do discurso social-ideológico dominante torna-se terreno fértil para a "produção da coesão social acompanhada da produção da coerção simbólica (da Lei social), cujo efeito maior é o de converter a todos em sujeitos (dessa Lei) - os sujeitos sociais." (SOUSA FILHO, 2007, p. 9). Em outras palavras, ser gordo, homossexual, negro ou estrangeiro representaria, no cotidiano escolar, uma afronta às imposições monoteístas reverberadas pela própria escola enquanto instituição que reifica o discurso social hegemônico da cultura nas subjetividades por ela abarcadas. Afinal de contas, como assevera Sousa Filho (2007):

O modo como a ideologia ordinariamente representa a realidade é uma tentativa de fazê-la aparecer como uma realidade-toda, e assim, igualmente, como uma verdade-toda, obscurecendo a existência do que lhe escapa e extrapola uma infinidade de elementos foracluídosda estruturação social [...] (SOUSA FILHO, 2007, P. 12).

O bullying é, em outras palavras, a expressão subjetiva dos elementos foracluídos da ordem social que sequer foram sancionados pelo simbólico e que, portanto, deveriam ser estigmatizados para não afetar a estabilidade da realidade social vigente (na escola). Não há no universo estudantil um espaço propício para a manifestação de formas de ser/agir do gordo, do negro, do gay, da lésbica, do nordestino etc. já que o regime das normalidades aceitas (imposto pelo discurso ideológico) promove o seu "modo de ser e agir" tidos como verdadeiros, necessários, únicos e corretos. São inúmeros os autores que atestam o bullying como uma manifestação de preconceitos e fobias dirigidas preferencialmente ao diferente, ao que destoa do modelo culturalmente venerado e tido com necessário pelo senso-comum. Senso-comum este que, conforme o próprio Sousa Filho (2007) é retroalimentado pela ideologia e todo seu ordenamento simbólico.

Por fim, cabe aqui concluir que o espectro ideológico é um artifício que se estende para além do fazer científico que pragmatiza a realidade bullying através da profusão de dados estatísticos e empíricos que a concebe. A própria realidade social e 

SUBJACENTE ATRAVÉS DO PENSAMENTO CONSTRUCIONISTA CRÍTICO Jairo José dos Santos Junior

sua ideologia acachapante reverberam seus discursos para além do cotidiano dos sujeitos, atingindo-os através das múltiplas instituições que a configuram (como a escolar, por exemplo), refletindo seu intento monoteizador das "verdades" e das "legitimidades" aceitas e vistas como necessárias, eternas, naturais, divinas, imodificáveis ou mesmo divinas sobre os modos de ser e agir dos sujeitos, verdadeiros operadores do discurso ideológico subserviente a dominação cultural e de suas formas e ordenamentos tão peculiares.

\section{A ALTERnATIVA CRÍtico-CONSTRUCIONISTA COMO PROPOSTA DE REFLEXÃO SOBRE O CONCEITO DE BULLYING ESCOLAR: UMA TRANSGRESSÃO A "METAFÍSICA DA SUBSTÂNCIA"}

Conforme dito na seção anterior, a ideologia é uma ferramenta de ofício da cultura, servindo a sua manutenção enquanto ordem hegemônica, estável e eterna. Todavia, o processo de estruturação social, ou seja, de produção simbólica que confere sentido ao mundo, cujas significações justificarão e legitimarão as formas estruturais da realidade social, também promove furos nesta mesma realidade (SOUSA FILHO, 2007). E estes furos consistem, mais precisamente, em aparições espectrais (ZIZEK, 1996) que emergem na realidade a partir dos elementos foracluídos que ficaram relegados ao real, ou seja, que em certo processo de estruturação social não foram admitidos em sua ordem simbólica. Tais furos ou rachaduras que desestabilizam a imagem ficcional da realidade (assegurada pela ideologia) culminam igualmente no fracasso desta ficção simbólica em sua tentativa de domesticar absolutamente a vida social e individual.

Tal fracasso, segundo Sousa Filho (2007), exprime-se através de transgressões frente à ordem instituída e sua ideologia. Em outras palavras:

Bem ao contrário, uma teoria da ideologia concebe igualmente o fracasso de parte da tentativa da ideologia em homogeneizar, controlar, colonizar a vida individual e coletiva. Os indivíduos, embora sob o domínio do discurso ideológico, reinterpretam e ressignificam a realidade, tornam-se pontos de resistência às ideias e às instituições sociais dominantes que representam 
O CONCEITO DE BULLYING ESCOLAR: UMA CRÍTICA À IDEOLOGIA SUBJACENTE ATRAVÉS DO PENSAMENTO CONSTRUCIONISTA CRÍTICO Jairo José dos Santos Junior

controle, sujeição, dominação, enquanto realizadoras da moralidade aceita, de padrões culturais, estruturas sociais. (SOUSA FILHO, 2007, p. 11).

Se esta falha acaba culminando em transgressões, como estas últimas se manifestariam na realidade? Através de rupturas, ultrapassagens ou superações ao arbitrário cultural imposto. Ou em outras palavras, através de manifestações individuais ou coletivas tidas como "chocantes", “imorais", promovidos em ambientes públicos ou privados, ou também de formas de expressão estética/visual/comportamental dos corpos enquanto instrumentos de "subversão" ao que está aí constituído e aceito. O bullying é uma forma de agressão pautada nas diferenças; e nunca ser diferente produziu tanta intolerância. Porém, um número cada vez maior de ações (individuais ou coletivas) vem potencializando a expressão da diversidade ou do discrepante na realidade social, inclusive em ambientes como aa própria escola.

A transgressão sobre o instituído configura-se como uma forma de manifestação que se dá através da expressão cultural da vida humana. Afinal de contas, o homem é um constructo histórico-social que encontra na cultura a ferramenta chave para a produção de sua existência. E tal produção não é fruto de uma suposta "metafísica da substância", ou seja, de substancialismos ou essencialismos que atribuem à existência humana uma elaboração a priori de sua origem e estabelecimento no mundo, feitas por entidades outras, divinas, sobrenaturais ou mesmo naturais, que outrora criaram o mundo e os seres que dele fazem parte (SOUSA FILHO, 2007, p. 2-12).

Tal metafísica ainda povoa o imaginário de muitos autores e ramos do saber que articulam o conceito de bullying dentro de um prospecto essencialista ou substancialista, no qual a natureza precede a cultura e, portanto, justifica os rompantes individuais de violência e de vitimismo dos protagonistas desta ação. Basta citar como exemplo, o texto de Almeida \& Medrado (2004, p.1) em que os autores, discorrendo sobre o papel dos agressores da violência bullying, afirmam que:

\footnotetext{
"Bully" que quer dizer brigão, valentão, tirano, exprime atitudes agressivas intencionais e repetitivas, que ocorrem sem motivação evidente, causando dor e intimidação em suas "vítimas". Pode-se aliar a isso a efervecência
} 
O CONCEITO DE BULLYING ESCOLAR: UMA CRÍTICA À IDEOLOGIA SUBJACENTE ATRAVÉS DO PENSAMENTO CONSTRUCIONISTA CRÍTICO Jairo José dos Santos Junior

hormonal e a necessidade de auto-afirmação, fatos típicos da adolescência podendo-se chegar a uma receita explosiva. (ALMEIDA \& MEDRADO, 2004, p.1 GRIFO NOSSO).

Este exemplo supracitado reforça o caráter essencialista e substancialista que permeia o "fazer científico" que subjaz a compreensão do fenômeno bullying. E mais: forma de fazer ciência esta que produz "verdades" que se pretendem inteiras, absolutas e sem abertura com outras correntes epistemológicas da ciência (ANTUNES \& ZUIN, 2008).

Nesta seção, o presente autor deste texto sugere uma nova forma de dialogar com o discurso científico hegemônico que produz as verdades sobre a fenomenologia bullying: o pensamento radical Construcionista. Tal teoria fundamenta-se no legado de muitos autores e trabalhos nos diversos campos em ciências humanas e sociais, assim como de filosofias. E um dos seus principais pressupostos é o da primazia da cultura e do social sobre o indivíduo humano: nada antes da cultura, da linguagem e do social fundaria os sujeitos, sendo estes produtos de sua própria ação no mundo (cultural e histórica). Em outras palavras:

\footnotetext{
O que funda o humano é o mundo dos objetos, signos, relações e instituições criados pelo próprio humano. Fora desse entendimento estão os idealismos e substancialismos de todos os matizes que propugnam causas e sujeitos fora da cultura e da história humana. (SOUSA FILHO, 2007, p. 8).
}

Sendo assim, sugerir o Construcionismo Crítico como forma de interpretar/problematizar as mediações sociais que transpassam a realidade da violência escolar bullying não é algo despropositado, quando se objetiva aqui ampliar o leque de possiblidades analíticas sobre o problema, dando-lhe uma feição humanística em termos epistemológicos. Atribuir a culpa do problema a supostas causas hormonais, cerebral ou mesmo orgânicas, consistiria em limitar-se a determinismos e substancialismosacachapantes que reforçariam a ideologia por trás desta intepretação discursiva oriunda das ciências médicas e biológicas. 


\title{
O CONCEITO DE BULLYING ESCOLAR: UMA CRÍTICA À IDEOLOGIA SUBJACENTE ATRAVÉS DO PENSAMENTO CONSTRUCIONISTA CRÍTICO Jairo José dos Santos Junior
}

Portanto, sugerir a Teoria Construcionista como fomento interpretativo sobre um tema tão dominado por outros ramos do saber configura-se como uma atitude transgressora que não objetiva destruir o discurso proeminente sobre o bullying, mas antes acrescentar valor para melhor intervir sobre esta forma de agressão, seus personagens e o contexto que os cerca. Por transgressão deve ficar claro:

\begin{abstract}
Não sendo nossa intenção traçar as linhas gerais de uma problemática bem mais complexa, reconhecemos as transgressões em termos de afirmações positivas (criativas) do desejo. Acreditamos que seja possível contrapor à concepção da transgressão como coisa negativa, fundada na idéia da renegação da ordem e na destruição, uma concepção baseada na afirmação positiva da diversidade, da pluralidade e da diferença do desejo, a qual se caracterizaria pelo que poderia ser chamado de transgressão criadora, positiva. Se transgressão significa a ação humana de ultrapassar, atravessar, exceder, o ato transgressor opera a ruptura com algo do mundo estabelecido, instituído, construído. Cada um, ao inventar, ao buscar, ao experimentar o ainda-não tentado, incorre em transgressão, implementação, criação do novo. Mudança da realidade, mudança do mundo humano. (SOUSA FILHO, 2007, p.13).
\end{abstract}

Neste sentido, a atitude transgressora se manifesta num duplo movimento: através da produção ficcional das individualidades de acordo com o reforço às suas diferenças (do destaque a valorização ao cabelo crespo como forma de valorização racial até manifestações políticas como o beijo gay coletivo); até o rompimento com o discurso hegemônico que produz as verdades supostamente inexoráveis sobre o bullying (discurso este oriundo principalmente das ciências médicas e biológicas). Em ambos os casos, a ideologia está presente: hora reforçando seus monoteísmos morais, sexuais, estéticos etc. Ora desqualificando as formas que, uma vez interditadas pela estruturação social, são classificadas no âmbito do patológico, do errado, do desviante. Desqualificações estas que reverberam constantemente no cotidiano dos indivíduos e cujos efeitos de sentido produzem preconceitos, perseguições e atitudes de hostilidade e agressão, sendo o bullying um exemplar claro deste processo de homogeneização forçada da realidade social e de suas relações. 


\section{O CONCEITO DE BULLYING ESCOLAR: UMA CRÍTICA À IDEOLOGIA SUBJACENTE ATRAVÉS DO PENSAMENTO CONSTRUCIONISTA CRÍTICO Jairo José dos Santos Junior}

\section{CONCLUSÃO}

Este artigo não se propõe esgotar peremptoriamente a discussão sobre a temática bullying e a crítica que necessariamente deve subjazer suas verdades aparentemente inquestionáveis.

Antes disto, o propósito do texto é enfatizar o caráter ideológico por trás do "fazer científico" que predomina nas análises sobre o bullying; apontar como tal ideologia, ao passo que se vincula epistemologicamente ao discurso que trata da fenomenologia em questão, também reforça seus monoteísmos nas práticas sociais e nas relações que configuram a agressão; e apontar como a Teoria Construcionista crítica surge não apenas como alternativa interpretativa que permita criticar e refletir sobre as mediações sociais que atravessam o fenômeno, mas também como atitude transgressora que rompe com a hegemonia epistemológica das ciências médicas/biológicas, atitude esta que também surge como alento a todo aquele que busca expressar suas diferenças como atitude de subversão e de valorização do diverso, do diferente, do destoante.

Embora o assunto possa se desdobrar para inúmeras possibilidades de análise e de discussão sob outros parâmetros científicos objetivou-se aqui lançar as bases que permitam a ruptura definitiva deste monopólio científico sobre a temática em questão, ampliando sua visualização de maneira transdisciplinar para outras dimensões do saber científico, tais como as ciências humanas. E o Construcionismo Crítico, como alternativa teórico-metodológica que granjeia de maneira sistematizada os saberes da área humanística, reflete-se como instrumento fundamental neste processo de crítica e desconstrução da noção de bullying e de seus fundamentos. 
O CONCEITO DE BULLYING ESCOLAR: UMA CRÍTICA À IDEOLOGIA SUBJACENTE ATRAVÉS DO PENSAMENTO CONSTRUCIONISTA CRÍTICO Jairo José dos Santos Junior

\section{REFERÊNCIAS}

ABRAMOVAY, M., \& Rua, M. G. Violências nas escolas: Versão resumida. Brasília, DF: UNESCO, 2002.

COSTANTINI, Alessandro. Bullying: como combatê-lo? - prevenir e enfrentar a violência entre jovens. São Paulo: Itália Nova, 2004.

FANTE, Cleo. Fenômeno bullying: como prevenir a violência nas escolas e educar para a paz. $2^{\mathrm{a}}$ ed. Campinas: Verus, 2005.

FANTE, Cleo; PEDRA, José Augusto. Bullying escolar: perguntas \& respostas. Porto Alegre: Artmed, 2008.

LOPES, A. A., Neto. (2005). Bullying: Comportamento agressivo entre estudantes. Jornal de Pediatria, 81(5), 164-172.

MARTINS, M. J. D. (2005). O problema da violência escolar: Uma clarificação e diferenciação de vários conceitos relacionados. Revista Portuguesa de Educação, 18(1), 93-105.

SMITH, P. K. (2002). Intimidação por colegas e maneiras de evitá-la. In E.

Debarbieux\& C. Blaya (Eds.), Violência nas escolas e políticas públicas (pp. 187205). Brasília, DF: Unesco.

SOUSA FILHO, A. Cultura, ideologia e violência- Contribuição a um debate sobre origens de formas da violência no Brasil. Sociabilidades, São Paulo, v.2, p. 129-153, 2003.

Mito e Ideologia. in: Comunicologia- Revista de Comunicação e

Epistemologia da Universidade Católica de Brasília. Ano 0, n. 01, 2006. http:// www.ucb.br 
O CONCEITO DE BULLYING ESCOLAR: UMA CRÍTICA À IDEOLOGIA SUBJACENTE ATRAVÉS DO PENSAMENTO CONSTRUCIONISTA CRÍTICO Jairo José dos Santos Junior

A. Por uma Teoria Construcionista Crítica. Bagoas: estudos gays - gêneros e sexualidades, v. 1, p. 27-59. Natal: EdUFRN; 2007.

SPOSITO, M. P. (2001). Um breve balanço da pesquisa sobre violência escolar no Brasil. Educação e pesquisa, 27(1), 87-103. 